\title{
Por trás do editorial: um estudo semiótico sobre o ator manifestante de rua
}

\author{
Marcos Rogério Martins Costa \\ Universidade de São Paulo (USP), Secretaria Municipal de Educação de São Paulo (SME-SP), \\ São Paulo, São Paulo, Brasil \\ marcosrmcosta15@gmail.com \\ http://orcid.org/0000-0002-4627-9989
}

DOI: $\underline{\text { http://dx.doi.org/10.21165/el.v47i3.1979 }}$

\section{Resumo}

Este estudo objetiva investigar o gênero editorial da cobertura jornalística resultante das manifestações populares de rua ocorridas em junho de 2013, nomeadas de Jornadas de Junho. Parte-se de uma perspectiva teórica interdisciplinar, pois se promove, principalmente, os pressupostos da semiótica francesa (GREIMAS; COURTÉS, 2008) e da filosofia bakhtiniana (BAKHTIN, 2006). Como corpus de análise, foram escolhidos os editoriais publicados nos dias 13, 15 e 20 de junho de 2013 dos jornais Folha de São Paulo e O Estado de São Paulo. A partir desse corpus, discute-se a estrutura temática e composicional do gênero e, então, analisa-se o estilo por meio dos distintos modos de tratar eticamente o ator do enunciado manifestante. Como resultado, depreende-se que o gênero editorial, ao se sustentar dominantemente no eixo do inteligível, desfavorece um acento sensível, o que não impede o enunciador, em seu estilo autoral (DISCINI, 2015), de sensibilizar seu enunciatário.

Palavras-chave: editorial; manifestante; sensível; inteligível; Jornadas de Junho.

\section{Behind the editorial: a semiotic study on the street protester actor}

\begin{abstract}
This study aims to investigate the editorial genre in the journalistic coverage resulting from the popular street protests that took place in June 2013, named June Protests. It is based on an interdisciplinary theoretical perspective, because the assumptions of the French semiotics (GREIMAS; COURTÉS, 2008) and Bakhtin philosophy (BAKHTIN, 2006) are promoted. As corpus of analysis, the editorials published on June 13th, 15th and 20th, 2013 were selected in the newspapers Folha de São Paulo and O Estado de São Paulo. From this corpus, the thematic and compositional structure of the genre is discussed, and then the style is analyzed based on the different ways of ethically treating the actor of the "protester" enunciate. As a result, it can be deduced that the editorial genre, by being dominantly based on the intelligible axis, does not favor a sensitive accent, and this does not prevent the enunciator, in his/her authorial style (DISCINI, 2015), from sensitizing his enunciatee.
\end{abstract}

Keywords: editorial; protester; sensible; intelligible; June protests.

\section{Considerações iniciais}

Pesquisas ulteriores [às primeiras reinterpretações linguísticas dos dramatis personae] permitiram enxergar a organização actancial das "personagens da narrativa" com um pouco mais de clareza e até mesmo vislumbrar a possibilidade de uma gramática narrativa que não dependesse das manifestações discursivas. A organização actorial, no entanto, quase não foi afetada por essas 
pesquisas; deficiência que se explica facilmente pela ausência de uma teoria coerente do discurso (GREIMAS, 2014, p. 62).

Em acordo com essas palavras do mestre lituano Algirdas Julien Greimas (19171992), publicadas pela primeira vez em 1983, buscamos colaborar para a expansão e a reformulação do modelo semiótico de análise do ator, mostrando a legitimidade e o rendimento da incorporação das circunstâncias perceptivas, sensíveis e afetivas da significação - sempre entendidas em suas condições linguageiras - no exame de uma dada interação polêmica, entre, de um lado, o ator da enunciação e, de outro, o ator do enunciado. Importa à investigação compreender o processo da configuração do enunciado para além de sua organização textual, promovendo, assim, o estudo das relações dialógicas das esferas de atuação humana no processo de construção do sentido. Para tanto, este artigo objetiva explorar a construção actorial do manifestante das Jornadas de Junho nos editoriais selecionados dos jornais O Estado de São Paulo (doravante Estado) e Folha de São Paulo (doravante Folha).

Entende-se ator, em uma acepção semiótica, como "o lugar de convergência e de investimento dos dois componentes, sintático e semântico. Para ser chamado de ator, um lexema deve ser portador de pelo menos um papel actancial e de no mínimo um papel temático" (GREIMAS; COURTÉS, 2008, p. 45). Os semioticistas sustentam, ainda, que o ator não é somente o lugar de investimento, mas também o de transformações, uma vez que o discurso se engendra como um jogo de aquisições e de perdas sucessivas de valores. E nesse jogo, o ator é uma das peças principais, porque exerce, como em qualquer narrativa, valorações judicativas e sensíveis, isto é, fundamenta-se como um dos nós resultantes dos direcionamentos do eixo do sensível com o do inteligível (cf. DISCINI, 2015).

Observar a atuação da imprensa e sua influência na opinião pública durante a cobertura das manifestações ocorridas em junho de 2013 é um objeto de estudo importante por diversos motivos, como já defendemos em outros momentos (COSTA, 2017, 2016a, 2016b). Essas manifestações são consideradas uma das maiores do período de redemocratização brasileiro, conforme sustentam os historiadores Secco (2013) e Nobre (2013). Outro fator importante é a relevância de se compreender como a própria dinâmica dos protestos foi interpretada pelos órgãos de comunicação legitimados socialmente.

Retomando a historicidade dos eventos, podemos destacar que, no início dos atos de protesto, promovidos pelo Movimento Passe Livre (MPL), os grandes veículos de comunicação realizaram uma cobertura jornalística que acentuava os aspectos prejudiciais das manifestações, por exemplo, a interrupção da mobilidade urbana na cidade e os atos de vandalismo que danificaram vidraças de bancos, estações de metrô, pontos de ônibus, dentre outros bens públicos e privados. Contudo, foram danos provocados por parte dos manifestantes que estavam nas ruas e não necessariamente pela maioria dos presentes nos protestos.

Grandes jornais, como o Estado e a Folha, publicaram editoriais e reportagens denominando os manifestantes como "baderneiros" (OESP, 2013a, p. A3) e "vândalos" (FSP, 2013a, p. A2). Esses periódicos, por exemplo, pediam mais rigor da polícia militar para que interviesse nos protestos a fim de impedir os atos de vandalismo e, consequentemente, evitar a depredação de bens públicos e privados. No mesmo dia 13 de junho de 2013, em que editoriais mais explicitamente contrários às manifestações foram 
publicados, a polícia militar agiu de forma extremada e truculenta nas ruas paralisadas pelo ato de protesto promovido pelo MPL. Depois desse protesto e da consequente repercussão de vídeos e imagens que registraram e documentaram a violência policial, os canais de comunicação, em especial, os jornais impressos da grande imprensa, como Estado e Folha, atenuaram seu posicionamento contrário às manifestações. Diante desse fenômeno, é justificável nosso interesse em estudar esse momento de instabilidade fórica e axiológica a partir dos gêneros jornalísticos já citados.

Para analisar esse fenômeno, selecionamos o gênero discursivo editorial (BAKHTIN, 2006), pois a própria estrutura linguística e ideológica delineia esse gênero. Primeiramente, é um gênero de caráter opinativo e, com isso, aponta, sustenta e projeta um posicionamento discursivo no mundo, ideologicamente marcado. Para tanto, ele tem uma organização de sentido nada ingênua: para enunciar a sua opinião, o conteúdo verbal é construído de forma indireta, ocultando e/ou amenizando o efeito de subjetividade. Por isso, o gênero não é assinado por um autor, mas o meio que o veicula dá a autoria ao texto. Essas características fazem desse gênero um rico material de estudo do fazer persuasivo da cobertura jornalística dos dois veículos de comunicação selecionados: o Estado e a Folha.

Podemos emparelhar o Estado e a Folha em uma mesma totalidade, pois ambos parecem apresentar proximidade de interesses em sua seleção e organização do mundo. Prova disso é que os dois projetam, em seus discursos, a predileção por temas afins, como política nacional (implementação de leis, revogações judiciais, eleições etc.), situação socioeconômica da nação (crise econômica, ajuste fiscal, aumento de tarifas etc.) e eventos de interesse nacional e internacional (Campeonato Brasileiro, Copa do Mundo, Olimpíadas etc.). Como acrescenta Discini (2009), esse núcleo temático, compartilhado pelos dois jornais no escopo da imprensa dita séria, demanda também um núcleo figurativo, no qual existem semelhanças e diferenças no modo de usar as figuras e os temas:

[...] esse núcleo temático [compartilhado por Estado e Folha] demanda um núcleo figurativo, em torno do qual gravitam variações temáticas e figurativas, fundando, nessa chamada imprensa séria, a dita configuração interdiscursiva, base da construção de um mesmo corpo, de um mesmo caráter, de uma mesma voz, retomando conceitos de Maingueneau. Firma-se, portanto, por meio dessa configuração interdiscursiva, uma recorrência discursiva, causa e consequência da totalidade estilística, em que uma enunciação se caracteriza não só pela escolha, mas pelo modo de usar temas e figuras (DISCINI, 2009, p. 120, grifo da autora).

Apoiados em Discini (2009), podemos afirmar que esses dois jornais, embora distintos em diversos aspectos, apresentam semelhanças em seu modo de apreciar os objetos e os valores em circulação, por isso, eles compartilham certas figuras e temas. Logo, ao tratarmos desses dois jornais em uma mesma totalidade discursiva, não estamos apagando suas diferenças, mas, diferentemente disso, constatando que existem invariâncias dentro das variâncias, como prevê a proposta hjelmsleviana para uma teoria da linguagem (HJELMSLEV, 2009).

Acrescentamos, ainda, que o gênero discursivo, na visada bakhtiniana, guarda o thesaurus da língua e o renova nas correias do discurso (BAKHTIN, 2006), ou seja, o gênero, enquanto estiver em uso, estará atrelado invariavelmente às coerções da língua e às subversões do discurso. Daí a importância de examinarmos essas relações genéricas 
para, em seguida, perscrutarmos o corpo actorial nos textos selecionados, uma vez que "a actorialização é um dos componentes da discursivização e constitui-se por operações combinadas que se dão tanto no componente sintáxico quanto no semântico do discurso" (FIORIN, 2010, p. 59). Isso evidencia a participação ativa da actorialização na relação língua/discurso e a necessidade de se estudar essa relação, o que fazemos a partir do exame dos componentes do gênero.

Podemos herdar o pensamento de Bakhtin no interior do projeto semiótico, resgatando os três componentes do gênero discursivo: "conteúdo temático, estilo, construção composicional” (BAKHTIN, 2006, p. 262). Ressaltamos que o conteúdo temático não é simplesmente o assunto sobre o qual se trata um determinado enunciado, mas o recorte responsivo do sujeito da enunciação sobre certo tema. Já a construção composicional diz respeito à estruturação geral interna do enunciado em diálogo com as escolhas de textualização e discursivização do sujeito da enunciação. $O$ estilo, por sua vez, corresponde ao tom volitivo-emotivo, utilizado pelo enunciador em sua interação com o enunciatário. Como podemos notar, em todos os casos, há a presença/intervenção do sujeito da enunciação - ora tácita, ora explícita.

Com efeito, os dois jornais recuperam muitas das características próprias do gênero editorial em seus textos, sem, com isso, deixarem de reiterar suas diferenças como veículos distintos e empresas concorrentes, pois continuam concebendo diferentes atores da enunciação, como podemos apreender pelos seus reiterados e variados modos de dizer e de predicar semanticamente o mundo natural e seus fenômenos.

Para realizar a análise desse gênero, partimos de uma perspectiva teórica interdisciplinar, porque se promovem, principalmente, os pressupostos da semiótica francesa (GREIMAS; COURTÉS, 2008; ZILBERBERG, 2011) e da filosofia bakhtiniana (BAKHTIN, 2006), respeitando a epistemologia de cada disciplina. Como corpus de análise, foram escolhidos os editoriais publicados nos dias 13, 15 e 20 de junho de 2013 dos jornais Folha e Estado. A partir desse corpus, discutimos a estrutura temática e composicional do gênero e, então, analisamos o estilo com base nos distintos modos de tratar eticamente o ator do enunciado manifestante.

Metodologicamente, dividimos este estudo em duas partes. Em um primeiro momento, discutimos as especificidades do gênero editorial partindo da definição temática e composicional do gênero discursivo. Em seguida, buscamos a definição do estilo no editorial, respectivamente, por meio da análise do ator do enunciado manifestante. Desse modo, se na primeira parte abordamos os aspectos gerais do gênero, na segunda, o foco é pela peculiar organização do sentido entre o enunciado e a enunciação no conjunto de textos selecionados. O percurso analítico é, conforme propõe a tradição semiótica, do geral para o particular, do mais complexo ao mais simples.

\section{Por trás da cobertura jornalística}

Consideramos a cobertura da imprensa como uma prática argumentativa, a qual reporta e inscreve no e pelo texto seus valores e seus posicionamentos axiológicos frente aos fatos e acontecimentos que são narrados/interpretados. Isso demonstra a importância de se refletir sobre a construção dos efeitos de realismo no enunciado enunciado (GREIMAS; COURTÉS, 2008). Por trás da cobertura jornalística, ratificamos que subjaz uma prática argumentativa a qual integra determinada estratégia adotada pelo sujeito da 
enunciação para formular seu referente, pois, como explica Landowski (1992, p. 13-14, grifo do autor), “embora as 'coisas' que tomamos por referentes tenham efetivamente a aparência de coisas, elas são signos, isto é, formas semioticamente complexas: não elementos primitivos in-analisáveis mas configurações estruturais a analisar enquanto construções".

Ao descrever as duas coberturas jornalísticas, a do Estado e a da Folha, propomos, então, traçar as relações dos usos de categorias valorativas e de suas respectivas práticas argumentativas. Como escopo de análise do gênero editorial, escolhemos aqueles publicados nos dias 13, 15 e 20 de junho de 2013 nos dois jornais selecionados. Reiteramos que os trechos selecionados em nossa análise foram coletados com base no critério de pertinência à temática das Jornadas de Junho, com interesse prioritário voltado à descrição do ator do enunciado manifestante.

Considerando esse corpus, o nosso intento é apreender a forma sintagmática das práticas semióticas que, com maior ou menor intensidade (ZILBERBERG, 2011), congregam os dois veículos de comunicação selecionados, possibilitando-nos entender a respectiva estratégia discursiva que os abarca. Em outras palavras, seguindo a proposta de Fontanille $(2008,2005)$, a análise semiótica pretendida para o gênero editorial investiga as práticas semióticas presentes e atuantes na produção e recepção dos textos examinados para que, reconhecidas essas práticas, possamos compreender $\mathrm{o}$ posicionamento discursivo da e na mídia impressa.

Por prática semiótica, entendemos "uma modificação dos corpos e das figuras, que implica uma sintaxe figurativa. O conjunto (papéis, atos, modalizações, paixões e sintaxe figurativa) constitui esse primeiro dispositivo [as práticas semióticas]" (FONTANILLE, 2008, p. 23). Eis, portanto, a nossa proposta: investigar o que há por trás das coberturas jornalísticas do Estado e da Folha a partir de seus gêneros discursivos neste artigo, em especial, os editoriais.

Ressalvamos que não recuperamos toda a estratégia articulada para sustentar o posicionamento do sujeito da enunciação sobre o ator do enunciado manifestante. O que resgatamos são as práticas mais frequentes dentro do corpus selecionado para esta pesquisa. Em outras palavras, depreendemos as invariâncias que subjazem às variações, uma vez que essa recorrência qualitativa no modo de ser e de fazer é mais relevante à construção referencial de uma identidade do que, por exemplo, a quantidade estatisticamente demonstrável de um mesmo elemento textual no enunciado, conforme prevê a perspectiva metodológica da semiótica francesa (GREIMAS; COURTÉS, 2008). Essa é, portanto, a metodologia descritiva aplicada à análise semiótica dos editoriais selecionados.

Sobre as características gerais do editorial, podemos afirmar que é um gênero concebido para expor a opinião de um grupo de pessoas e/ou instituição. Esse é um dos motivos que justifica ele não ser assinado. Caso houvesse a autoria de um indivíduo fosse ele uma personalidade, ou um desconhecido, ou ainda, ocupasse qualquer um dos cargos/funções dentro da organização promotora do texto -, isso imputaria determinada individualidade. Logo, percebemos que esse gênero, tematicamente, é voltado para um coletivo, seja do lado de quem o escreve (enunciador do texto/organização), seja de quem o lê (enunciatário/público-leitor).

Outro fator bastante característico desse gênero é sua perspectiva argumentativa. Ao longo de todo texto, o enunciador vai elencar estatísticas, exemplos do cotidiano, fatos 
históricos e outros dados para convencer seu enunciatário de que está certo no que diz e percebe no mundo. Por isso, a meta persuasiva do editorial é condição sine qua non para a estrutura temática e composicional de seu texto, interferindo, assim, desde a sua concepção até a publicação.

Além disso, é um gênero que, ao usar a língua(gem), faz escolhas que preferem a clareza, a coerência, a coesão e o padrão culto da língua, não por uma questão de estilo, mas para convencer o maior número de leitores possível. Para tanto, o enunciador trabalha, com esmero, para reduzir as duplas interpretações e as frases subjetivas, tudo para que o enunciatário sinta, ao ler, que aquilo que foi dito era o mais óbvio possível a dizer sobre aquele tema e objeto de notícia. Esse é um dos recursos mais utilizados pela mídia - em especial, a imprensa impressa - para atrair, manter e aumentar seu públicoleitor.

A construção composicional desse gênero se serve tanto das notícias já veiculadas nas edições passadas, quanto daquelas que são previstas a serem enunciadas durante a leitura do jornal daquele dia. Assim, o editorial é, semioticamente, o conector dos temas e das figuras do veículo em que ele é publicado. Por isso, em estudos anteriores, sustentamos ser um gênero que predominantemente narra o ser e o estar no mundo retomando as memórias do acontecido (COSTA, 2016a), apoiados na proposta de Pessoa de Barros (2011), porque, para o enunciador do editorial, tudo já aconteceu, até o que está publicado na edição em que seu texto encontra-se impresso.

Essa característica de temporalidade dá ao enunciador do editorial ainda mais competência argumentativa. Ele sabe o que foi dito, o que vai ser dito nessa edição e, ainda, o que poderá ser dito nas próximas edições, de acordo com a linha editorial do veículo. Ele pode retomar, omitir ou responder aos fatos desta edição ou aos das anteriores. Em outras palavras, "o editorial pode se nutrir das manchetes e de notícias dos dias anteriores também. Por isso, na temática do gênero editorial, o escopo do contexto pragmático é maior [...]. Em outros termos, os interdiscursos aparecem mais no contrato fiduciário do texto do editorial [...]" (COSTA, 2016b, p. 164) ${ }^{1}$.

Compreendidas essas características gerais que constituem o gênero editorial no que se refere ao seu tema e a sua construção composicional, no próximo tópico, exploramos como esse gênero funda seu estilo. Para tanto, como objeto de estudo, selecionamos o ator do enunciado manifestante. Procuramos, com base nesse objeto, verificar os diversos e distintos modos de tratamento ético que o enunciador realiza ao longo do texto em três publicações dos dois jornais selecionados, Folha e Estado.

\section{Manifestante: distintos modos de tratar eticamente o ator do enunciado}

Durante as Jornadas de Junho, distintos foram os modos de tratar estética e eticamente o ator do enunciado manifestante. A militante Judensnaider e outros membros do MPL relatam que, a partir do dia 14 de junho de 2013, "depois de terem participado ativamente da campanha por mais rigor na repressão aos manifestantes, os grandes veículos de comunicação são agora levados a reportar a escalada da violência policial da

\footnotetext{
${ }^{1}$ Utilizamos o termo contexto pragmático conforme a concepção bakhtiniana, entendida em uma visada discursiva. Para tanto, como propõe Discini (2015), compreendemos que esse conceito remete aos (inter)discursos presentes e resgatados pelo estilo do gênero e pelo estilo autoral no processo de elaboração de um texto, nesse caso do editorial.
} 
qual os protestos foram alvo" (JUDENSNAIDER et al., 2013, p. 104). Para examinar esse momento de instabilidade da opinião pública e midiática sobre os atos de protesto promovidos inicialmente pelo MPL, buscamos nesse tópico investigar como $o$ manifestante foi construído na mídia impressa dentro do gênero editorial, respectivamente, em três publicações do Estado e da Folha nos dias 13, 15 e 20 de junho de 2013.

Anteriormente a esse momento, relatado por Judensnaider et al. (2013) - mas também reiterado por Moreira e Santiago (2013) e Murano (2013), dentre outros estudiosos e comentaristas -, no dia 13 de junho de 2013, a mídia impressa resgatou, disforicamente, os acontecimentos referentes ao terceiro ato de protestos contra o aumento da tarifa dos transportes públicos, realizado no dia 11. Os atos começaram no dia 6 de junho, devido ao novo valor, efetivado em São Paulo/SP no dia 2 do mesmo mês. Até aquele momento, as manifestações não haviam alcançado os números expressivos da casa dos milhões de participantes, uma vez que se reuniram nas ruas por volta de dez mil pessoas, segundo as estimativas da Polícia Militar de São Paulo e do Datafolha, em dados publicados na edição do dia 19 de junho na Folha.

Os editoriais do Estado e da Folha desse dia 13 fazem eco um em relação ao outro, pois ambos trazem palavras de ordem em suas manchetes. Temos, respectivamente, os seguintes títulos: "Chegou a hora do basta" e "Retomar a Paulista". As duas expressões trazem uma narrativa mínima. No caso do Estado, temos "a hora do basta". De acordo com o Dicionário eletrônico Houaiss (2014), o verbete basta exprime "ordem de interromper ou cessar imediatamente o que se está fazendo", ou seja, o enunciador deve terminar uma ação em andamento, no caso, as manifestações. O título "Retomar a Paulista", da Folha, já traz a narrativa de que algo foi tomado e é preciso re-tomar. No caso, o objeto a ser recuperado é a Avenida Paulista, local em que as manifestações de protesto do MPL estão ocorrendo. Comparando os dois títulos, ambos concordam a respeito de que algo precisa ser feito em relação às manifestações, conclamando pelo fim dessa mobilização, seja porque chegou a hora do basta, seja porque se precisa retomar a Paulista.

Além de uma ordem, os dois títulos podem ser interpretados como um pedido ou um conselho. Nas três possibilidades, há a imagem de um enunciador bastante competente, no sentido semiótico. Isso decorre, pois, em uma primeira vista, depreendese um sujeito que tem credibilidade para pedir (eis a modalidade do crer). Em seguida, também se percebe existir um sujeito que possui o conhecimento necessário para aconselhar (eis outra competência, a do saber). Então, em um terceiro viés, nota-se um sujeito que pressupõe ter a competência necessária para mandar (eis a modalidade do poder).

A imagem do enunciatário, por sua vez, é construída seguindo essas três possibilidades interpretativas: é aquele que pode aderir ou não ao pedido; é aquele que pode aceitar ou não o conselho; ou é aquele que pode aceitar ou não a ordem. Podemos observar que, nos dois editoriais, ambos publicados no dia 13/06/2013, o enunciador manipula o enunciatário a entrar em conjunção com o seu pedido/conselho/ordem.

Esses editoriais tratam os participantes dos atos de protesto como uma massa homogênea e, para isso, fazem uso de pelo menos dois recursos discursivos. O primeiro é destacar determinadas características do ator manifestante ao utilizar adjetivos substantivados para nomeá-los e/ou defini-los. Por exemplo, ao invés de dizer 
manifestantes baderneiros, ou simplesmente manifestante, a escolha é por apresentar apenas um adjetivo substantivado acompanhado de artigo definido: os baderneiros. Podemos observar esse recurso nos seguintes excertos:

(1) No terceiro dia de protesto contra o aumento da tarifa dos transportes coletivos, os baderneiros que o promovem ultrapassaram, ontem, todos os limites [...] (OESP, 2013a, p. A3, grifo nosso).

(2) Atacada com paus e pedras sempre que tentava conter a fúria dos baderneiros [...] (OESP, 2013a, p. A3, grifo nosso).

(3) São jovens predispostos à violência por uma ideologia pseudorrevolucionária, que buscam tirar proveito da compreensível irritação geral com o preço pago para viajar em ônibus e trens superlotados (FSP, 2013a, p. A2, grifo nosso).

(4) Cientes de sua condição marginal e sectária, os militantes lançam mão de expediente consagrado pelo oportunismo corporativista: marcar protestos em horário de pico de trânsito na Avenida Paulista, artéria vital da cidade (FSP, 2013a, p. A2, grifo nosso).

Esses excertos evidenciam um enunciador que, ao nomear, atribui valores e crenças sobre o ator do enunciado manifestante como aquele que é baderneiro, predisposto à violência por uma ideologia pseudorrevolucionária, ciente de sua condição marginal e sectária - para citar apenas as adjetivações presentes nos excertos selecionados. Ressaltamos que essa disforia se espalha por toda a edição do dia 13 de junho no Estado e na Folha, e ganha proporções e matizes cada vez mais pejorativos. Com isso, podemos observar a axiologia construída pelo sujeito da enunciação sobre o ator do enunciado desde o momento de nomeação deste. Ressaltamos que esse recurso não se restringe a essas duas publicações; ele é recorrente nas demais edições, publicadas nos dias 15 e 20 de junho de 2013, nas quais também se encontram adjetivações e substantivos abstratos representativos do campo semântico da violência (vandalismo, arruaceiros, violência etc.):

(5) Foi a manifestação mais violenta - pela insistência dos seus integrantes em ocupar vias, como a Avenida Paulista, que as autoridades haviam decidido manter livres [...] (OESP, 2013b, p. A3, grifo nosso).

(6) Os arruaceiros berravam "sem moralismo" e "sem burguesia". A ampla maioria civilizada não conseguia, tampouco, enfrentar os grupos que se puseram a vandalizar ou a saquear as lojas de departamentos das proximidades (OESP, 20013c, p. A3, grifo nosso).

(7) [...] mais grave que $o$ vandalismo e a violência dos manifestantes [...] (FSP, 2013b, p. A2, grifo nosso).

(8) De outro, novos e repetidos atos de vandalismo se registraram [nas manifestações] (FSP, 2013c, p. A2, grifo nosso).

Observando os excertos, podemos concluir que o enunciador, para julgar negativamente os atos de protesto realizados, associa o campo semântico da violência a eles. Acrescentamos, também, que o enunciador define, de maneira muito genérica, os manifestantes como um grupo. Com isso, o ator do enunciado vai sendo construído de modo a confirmar a axiologia do ator da enunciação, uma vez que o ator manifestante adquire determinadas competências disfóricas e realiza contraprogramas que o qualificam negativamente. 
Outro recurso utilizado para categorizar o ator manifestante é atribuir-lhe características baseadas na relação de causa e efeito construída no encadeamento de ações e fatos no enunciado. Para isso, os editoriais, em geral, emparelham a ação de protesto de um determinado grupo de manifestantes aos efeitos negativos gerados para a grande coletividade, como congestionamento, violência, depredação, dentre outros malefícios. Esse recurso podemos observar nos trechos a seguir:

(9) Por onde passaram, os cerca de 10 mil manifestantes deixaram um rastro de destruição - pontos de ônibus, lojas, nove agências bancárias e ônibus depredados ou pichados. Uma bomba foi jogada na Estação Brigadeiro do Metrô e a Estação Trianon teve os vidros quebrados. Em algumas das ruas e avenidas por onde circularam, principalmente a Paulista, puseram fogo em sacos de lixo espalhados para impedir o trânsito e dificultar a ação da Polícia Militar (PM) (OESP, 2013a, p. A3, grifo nosso).

(10) Em suma, foi mais um dia de cão, pior do que os outros, no qual a violência dos manifestantes assustou e prejudicou diretamente centenas de milhares de paulistanos que trabalham na Paulista e no centro e deixou apreensivos milhões de outros que assistiram pela televisão às cenas de depredação (OESP, 2013a, p. A3, grifo nosso).

(11) Oito policiais militares e um número desconhecido de manifestantes feridos, 87 ônibus danificados, $R \$ 100$ mil de prejuizos em estações de metrô e milhões de paulistanos reféns do trânsito. Eis o saldo do terceiro protesto do Movimento Passe Livre (MPL), que se vangloria de parar São Paulo - e chega perto demais de consegui-lo (FSP, 2013a, p. A2, grifo nosso).

(12) O direito de manifestação é sagrado, mas não está acima da liberdade de ir e vir - menos ainda quando o primeiro é reclamado por poucos milhares de manifestantes e a segunda é negada a milhões (FSP, 2013a, p. A2, grifo nosso).

Nos excertos 9 a 12, verificamos que o enunciador consegue, de maneira implícita, justificar seu posicionamento contrário às manifestações e, de maneira explícita, responsabilizar os manifestantes pelas ações e fatos relatados, os quais, em sua quase totalidade, são negativos e pejorativos. Ao utilizar esse recurso, os manifestantes são entendidos e interpretados na visada do sujeito da enunciação como um ator coletivo realizador de contraprogramas, portanto, narrativamente, um antissujeito, visto que contraria os programas do ator coletivo sociedade.

Com esses dois recursos, os editoriais apequenam as manifestações e seus participantes, uma vez que os comparam com um contingente de pessoas que superam quantitativamente qualquer grupo de indivíduos e, além disso, constroem-nos a partir de uma disforia que está apoiada principalmente pelo campo semântico da violência. Para afirmar isso, a Folha, por exemplo, nomeia os manifestantes e as manifestações de "grupelho" (FSP, 2013a, p. A2), "facções" (FSP, 2013b, p. A2), "revolta" (FSP, 2013c, p. A2). Esses substantivos diminuem a representatividade do grupo, qualificam-no como partido insurreto e insubordinado, respectivamente. O Estado, por sua vez, nomeia de "baderna" (OESP, 2013a, p. A3), "radicais" (OESP, 2013a, p. A3), "espontaneístas" (OESP, 2013c, p. A3). Esses substantivos compartilham traços semânticos, respectivamente, com a desordem, o extremado e, por fim, o que se exprime irrefletidamente, conforme o Dicionário eletrônico Houaiss (2014). 
Para legitimar-se como voz imponente e importante do debate público, ambos os editoriais sustentam uma mesma proposta: maior rigor das autoridades frente às manifestações e seus manifestantes. Podemos perceber isso em diversos momentos, dentre os quais, selecionamos alguns:

(13) [...] ou as autoridades determinam que a polícia aja com maior rigor do que vem fazendo, ou a capital paulista ficará entregue à desordem, o que é inaceitável (OESP, 2013a, p. A3, grifo nosso).

(14) O fato é que a população quer o fim da baderna - e isso depende do rigor das autoridades (OESP, 2013a, p. A3, grifo nosso).

(15) É hora de pôr um ponto final nisso. Prefeitura e Policia Militar precisam fazer valer as restrições já existentes para protestos na Avenida Paulista, em cujas imediações estão sete grandes hospitais (FSP, 2013a, p. A2, grifo nosso).

(16) A depender de horário e número previsto de participantes, o poder público deveria vetar as potencialmente mais perturbadoras e indicar locais alternativos (FSP, 2013a, p. A2, grifo nosso).

Nesses excertos, evidenciamos o posicionamento desfavorável aos protestos, bem como o lugar ocupado pelo sujeito da enunciação: aquele que pode pedir, aconselhar e, até, mandar. Se resgatarmos os verbos dos excertos 15 e 16, verificaremos que eles pertencem à ordem do dever: "precisam fazer"; "deveria vetar". No caso dos excertos 13 e 14, eles exigem, de maneiras diferentes, o mesmo: mais rigor das autoridades. No excerto 13, temos duas orações coordenadas alternativas que evidenciam as duas hipóteses: a euforizada pelo enunciador, que é topicalizada, e a disforizada, que é enunciada em tom de ameaça, na qual se oferece ao enunciatário um objeto nocivo. No excerto 14, o enunciador fala como se fosse o porta-voz legítimo, transmitindo o desejo da população, que no caso seria pelo enrijecimento das normas de controle, promovidas pelas autoridades competentes - figurativizadas, no trecho 15 , pela Polícia e pela Prefeitura.

É importante ressaltar que a solicitação de maior rigor presente nas duas publicações do dia 13 de junho surtiu efeito. De fato, menos pessoas foram às manifestações no dia 13 de junho - de próximos a 10 mil, passaram para cerca de 2 mil pessoas, conforme estimativas da Polícia Militar de São Paulo. Em contrapartida, mais policiais compareceram às manifestações e, mais do que isso, houve mais conflitos entre manifestantes, policiais e não manifestantes - inclusive repórteres e transeuntes foram agredidos e feridos durante os confrontos. Como explica Secco (2013, p. 74), o quarto ato "ainda foi pequeno, mas a repressão policial desencadeou uma onda de solidariedade ao MPL, o que levou ao ato seguinte cerca de 250 mil pessoas. $O$ sexto ato manteve parte do ímpeto (18 de junho) e, logo depois, os governos reduziram as tarifas de ônibus e metrô". Esse abrupto aumento na participação dos atos após o dia 13 de junho de 2013 foi acompanhado pelo aumento no número de matérias jornalísticas que tratavam do tema das manifestações de rua na cidade de São Paulo/SP e em outras localidades do país, como podemos verificar no gráfico a seguir: 


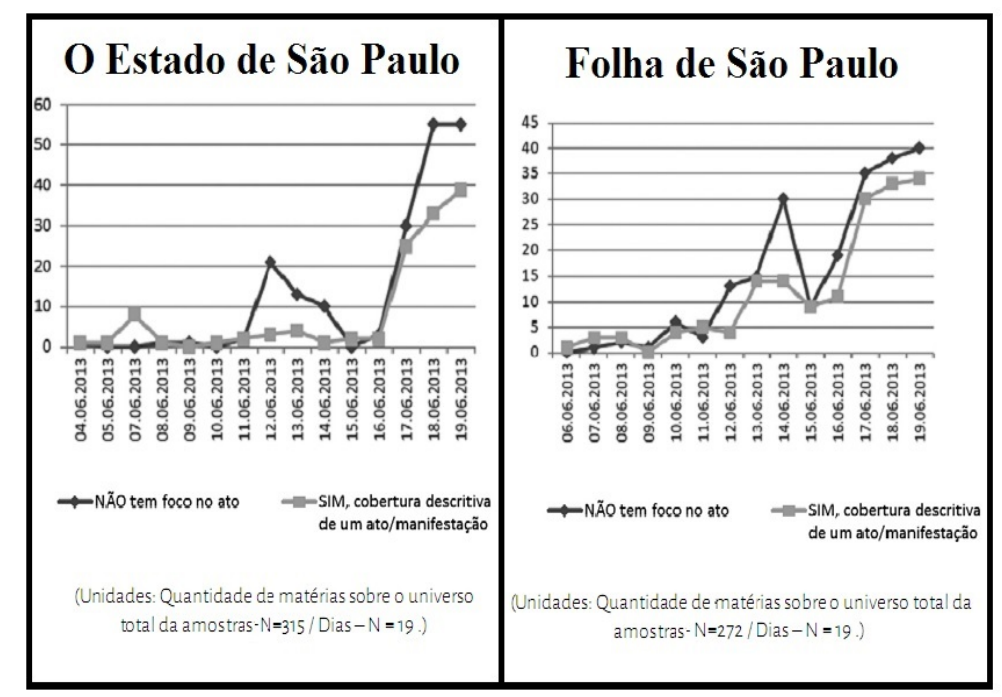

Figura 2. Panorama da cobertura das Jornadas de Junho em O Estado de São Paulo e Folha de São Paulo

Fonte: Intervozes - Coletivo Brasil de Comunicação Social (2014, p. 26, 36)

De acordo com os gráficos, foram coletadas 315 matérias no Estado e 272 na Folha, em 19 dias. Nesse período, houve dois grandes picos de aumento da quantidade de matérias com foco nos atos/manifestações: no Estado, nos dias 7 e 18, e na Folha, nos dias 14 e 19 de junho. Temos, no geral, um cenário de aumento da cobertura das Jornadas de Junho nos dois jornais. Esses dados evidenciam tanto a crescente participação desses veículos no debate sobre as manifestações de rua iniciadas na capital paulista quanto o interesse alternado desses veículos de comunicação por esse tema: ora divulgam massivamente, ora não. Há, assim, a presença de um tom volitivo-emotivo que seleciona e se interessa por determinados fatos em detrimento de outros, podendo ou não mudar essa postura valorativa. Podemos constatar isso por meio da oscilação na quantidade de matérias sobre os atos/manifestações nos dois jornais.

O tom volitivo-emotivo está presente no texto jornalístico, seja pela presença (no sentido de mais euforia, mais participação), seja pela ausência (no sentido de mais disforia, menos participação) no discurso e no debate dos fatos. Portanto, como prevê este estudo, o texto jornalístico não está isento de estesia, pois, como afirma Fiorin (1999, p. 111), "é um equívoco pensar que o leitor não possa ter uma estesia, uma fusão com esse objeto". O que diferencia o discurso da vida do discurso da arte é, como sustentamos, o maior ou menor distanciamento do contexto pragmático (cf. VOLOSHINOV, 1976; COSTA, 2016a), bem como a predominância da verossimilhança interna ou externa (cf. DISCINI, 2009; BAKHTIN, 2010), uma vez que há um continuum entre o mais mimético e o mais poético (FIORIN, 2008).

Diante desse panorama, é importante examinarmos a maneira como a mídia impressa, no caso do gênero editorial, acompanhou essa reconfiguração da mobilização popular e do poder público, porque, como vimos, um dos argumentos utilizados foi o de que as manifestações eram constituídas de grupelhos, facções, radicais, baderneiros. Como percebemos pelos excertos 13 a 16, muito do que foi realizado discursivamente nos editoriais do dia 13 encontraram recorrência nos editoriais dos dias 15 e 20 de junho. $\mathrm{O}$ que mudou no cotejo desses últimos frente aos dois primeiros foi o modo de articular a oposição e o número de seus oponentes. Se nos primeiros editoriais se opuseram 
manifestantes e sociedade, nos editoriais ulteriores confrontaram-se manifestantes, policiais e sociedade. Em termos semióticos, mudam-se os investimentos semânticos, mas os actantes e os programas narrativos são mantidos. Por isso, na superficialidade discursiva, parece que os editoriais dos dois jornais repudiaram a violência, independentemente de onde ela se originou: seja da parte dos manifestantes, seja da dos policiais, como podemos constatar pelos seguintes trechos:

(17) Foi a manifestação mais violenta - pela insistência dos seus integrantes em ocupar vias, como a Avenida Paulista, que as autoridades haviam decidido manter livres, e pela reação da Polícia Militar (PM), muito mais dura que nos dias anteriores (OESP, 2013b, p. A3, grifo nosso).

(18) A polícia, que na segunda-feira atirou em quem não devia, porque não fizera nada de errado ou nem sequer participava do protesto, dessa vez só apareceu com três horas de atraso, quando o pior já ocorrera. Se antes faltou policiar os PMs, depois sobrou desorientação - a começar do governador Geraldo Alckmin (OESP, 2013b, p. A3, grifo nosso).

(19) No quarto protesto, a responsável maior pela violência passou a ser a própria PM. Pessoas sem envolvimento no confronto foram vítimas da brutalidade policial. Transeuntes, funcionários do comércio, manifestantes pacíficos e até frequentadores de bar foram atacados com cassetetes e bombas (FSP, 2013b, p. A2, grifo nosso).

(20) De um lado, a truculência policial verificada na quinta-feira passada despertou largos contingentes da classe média para o movimento. De outro, novos e repetitivos atos de vandalismo se registraram. Entre o excesso e a omissão policial, o comando do Estado parecia oscilar, incapaz de definir-se quanto à alternativa de menor custo eleitoral (FSP, 2013 c, p. A2, grifo nosso).

Nos quatro excertos, podemos notar que a oposição não é mais entre o poder público e os manifestantes, mas entre os manifestantes, os policiais e o poder público. Se antes os policiais estavam em sintonia com o poder público, agora, na visão daquele que enuncia, os policiais agem de um modo e o poder público de outro, como se fossem entidades independentes. Essa autonomia não está prevista na Constituição Federal, de 1988, uma vez que as instituições policiais fazem parte do poder público e estão filiadas e subordinadas a um órgão da federação. No caso da Polícia Militar, a corporação está subordinada ao governo estadual (cf. BRASIL, 2015). Isso demonstra que o discurso (re)cria o mundo e seus valores.

\section{Considerações finais}

No mundo discursivizado pela mídia impressa, apoiada no gênero editorial, o ator do enunciado manifestante é construído de maneira disfórica, isto é, negativa. Por isso, o que constatamos não foi a euforização do ator manifestante, mas verificou-se a manutenção da disforização sobre o ator manifestante porque este ora é criminalizado, ora é questionado por suas pautas e seus interesses. Logo, contrariamente ao que foi ressaltado por Moreira e Santiago (2013) e enfatizado por Judensnaider et al. (2013), dentre outros comentadores, não houve, nos editoriais analisados, uma reviravolta no posicionamento axiológico dos dois representantes da mídia impressa em relação aos manifestantes: eles continuaram a disforizar os manifestantes, tendo diminutas atenuações nas edições dos dias 15 e 20 de junho. O que mudou, de fato, foi o 
posicionamento do editorial frente à atuação policial, depois do quarto ato (13 de junho): antes, eles a incentivavam, exigindo mais rigor; depois, eles a criticaram devido aos seus excessos.

Podemos destacar que isso ocorreu pela própria construção do discurso. Lembremos que, para afirmar e afiançar uma axiologia sobre um determinado sujeito e/ou objeto, o enunciador elabora seus contratos fiduciário e manipulatório com $\mathrm{o}$ enunciatário. É a partir desses contratos que o enunciador propõe uma mirada sobre a realidade, ou melhor, sobre o efeito de realidade. Nesse efeito de realismo (GREIMAS; COURTÉS, 2008), o enunciador escolhe e organiza determinados valores, objetos e circunstâncias, para garantir e conservar tanto sua credibilidade (fazer-crer) quanto sua manipulação (fazer-fazer).

Dessa configuração ética, podemos depreender uma estética: a predominância da verossimilhança externa. Isso ocorre porque o enunciador tenta a todo custo controlar e prever todas as possibilidades do texto, seja em sua relação de manipulação e fidúcia com o enunciatário, seja em sua relação estética e ética com o ator do enunciado manifestante. Por isso, como vimos, as manifestações populares de rua podem ser maiores ou menores, o que delas vai se dizer pode ser reconstruído e recontado de muitas maneiras, dependendo, em não raras vezes, muito pouco dos fatos em si.

O enunciado a ser produzido dependerá muito mais das relações travadas entre o enunciador-jornal e o enunciatário-leitor, as quais são, como se constata, permeadas de interdiscursos e coerções socioculturais. Por isso, temos um mínimo de estesia e o máximo de contexto pragmático (VOLOSHINOV, 1976), tendo, assim, um espaço diminuto para a fratura do cotidiano, em termos semióticos (GREIMAS, 2002). Isso também explica o porquê de se reiterar a descontinuidade no texto para fundar a argumentação: "[...] a projeção do descontínuo no contínuo é a primeira condição da inteligibilidade do mundo" (GREIMAS; COURTÉS, 2008, p. 127).

O gênero editorial, ao se sustentar dominantemente no eixo do inteligível, desfavorece um acento sensível. O que não impede o enunciador, em seu estilo autoral (DISCINI, 2015), de sensibilizar seu enunciatário, todavia se faz isso por meio de uma verossimilhança externa (DISCINI, 2009), que, colada ao contexto pragmático, (re)cria os motes passionais no e pelo texto. Percebemos isso nos textos analisados principalmente pelos usos lexicais na constituição das figuras do discurso, ou seja, quando se nomeou um grupo heterogêneo de manifestantes de "radicais" (OESP, 2013a) ou de "grupelho" (FSP, 2013a), dentre outros exemplos apresentados. Fica cada vez mais patente que, muitas vezes, a maneira de dizer fala mais do que o próprio dito.

\section{REFERÊNCIAS}

BAKHTIN, M. M. Para uma filosofia do ato responsável. Tradução de Valdemir Miotello e Carlos Alberto Faraco. São Carlos: Pedro \& João Editores, 2010.

Gêneros do discurso. In: Estética da criação verbal. Tradução de Paulo

Bezerra. 4. ed. São Paulo: Martins Fontes, 2006. p. 261-306.

BRASIL. Constituição da República Federativa do Brasil (atualizada até a emenda constitucional $n^{\circ}$ 88, de 7 de maio de 2015) e Constituição do Estado de São Paulo 
(atualizada até a emenda constitucional no 40, de 9 de abril de 2015). São Paulo: Imprensa Oficial; Governo do Estado de São Paulo, 2015.

COSTA, M. R. Memória e tensividade: as Jornadas de Junho de 2013 na charge e no editorial. Estudos semióticos. São Paulo, v. 12, n. 1, p. 43-54, jul. 2016a. Disponível em: $<$ http://www.revistas.usp.br/ esse/article/view/120536/118139>. Acesso em: 26 jun. 2018 .

O corpo do manifestante das Jornadas de Junho de 2013: a charge e o editorial da Folha de São Paulo. Galáxia. São Paulo, n. 33, p. 158-170, set.-dez. 2016b. Disponível

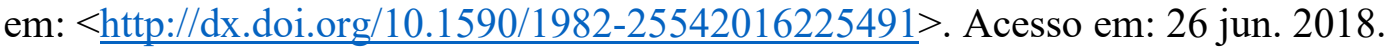

Cobertura jornalística das Jornadas de Junho: um estudo interdisciplinar. Estudos linguísticos, São Paulo, v. 46, n. 3, p. 1225-1241, 2017. Disponível em: $<$ https://revistas.gel.org.br/estudos-linguisticos/article/view/1522/1266> $>$. Acesso em: 26 jun. 2018.

DISCINI, N. Corpo e estilo. São Paulo: Contexto, 2015.

Contexto, 2009.

O estilo nos textos: história em quadrinhos, mídia e literatura. 2. ed. São Paulo:

FIORIN, J. L. Astúcias da enunciação: as categorias de pessoa, tempo e espaço. 2. ed. São Paulo: Ática, 2010.

Em busca do sentido: estudos discursivos. São Paulo: Contexto, 2008.

. Objeto artístico e experiência estética. In: LANDOWSKI, E.; DORRA, R.; OLIVEIRA, A. C. (Orgs.). Semiótica, estesis, estética. São Paulo: EDUC; Puebla: UAP, 1999. p. 101-117.

FONTANILLE, J. Práticas semióticas: imanência e pertinência, eficiência e otimização. In: DINIZ, M. L. V. P.; PORTELA, J. C. (Orgs.). Semiótica e mídia: textos, práticas, estratégias. Bauru: UNESP/FAAC, 2008. p. 15-74.

. Significação e visualidade: exercícios práticos. Tradução de Elizabeth Bastos Duarte e Maria Lília Dias de Castro. Porto Alegre: Sulina, 2005.

FSP - FOLHA DE SÃO PAULO. Retomar a Paulista. Folha de São Paulo. 13 jun. $2013 \mathrm{a}$. Opinião, p. A2.

Agentes do caos. Folha de São Paulo. 15 jun. 2013b. Opinião, p. A2.

Vitória das ruas. Folha de São Paulo. 20 jun. 2013c. Opinião, p. A2.

GREIMAS, A. J. Sobre o sentido II: ensaios semióticos. Tradução de Dilson Ferreira da Cruz. São Paulo: Nankin; Edusp, 2014.

Hacker, 2002.

Da imperfeição. Tradução de Ana Claudia Mei Alves de Oliveira. São Paulo:

GREIMAS, A. J.; COURTÉS, J. Dicionário de semiótica. Tradução de Alceu Dias Lima et al. São Paulo: Contexto, 2008.

HJELMSLEV, L. Prolegômenos a uma teoria da linguagem. Tradução de J. Teixeira Coelho Netto. São Paulo: Perspectiva, 2009. 
INSTITUTO ANTÔNIO HOUAISS. Dicionário Houaiss eletrônico da língua portuguesa. CD-ROM. Rio de Janeiro: Instituto Houaiss; Editora Objetiva, 2014.

INTERVOZES - COLETIVO BRASIL DE COMUNICAÇÃO SOCIAL. Vozes silenciadas - mídia e protestos: a cobertura das manifestações de junho de 2013 nos jornais $O$ Estado de $S$. Paulo, Folha de S. Paulo e $O$ Globo. São Paulo: Intervozes Coletivo Brasil de Comunicação Social, 2014.

JUDENSNAIDER, E. et al. Vinte centavos: a luta contra o aumento. São Paulo: Veneta, 2013.

LANDOWSKI, E. A sociedade refletida: ensaios de sociossemiótica. Tradução de Eduardo Brandão. Campinas: EDUC-Pontes, 1992.

MOREIRA, O. de L.; SANTIAGO, I. M. F. L. Vem pra rua: os protestos de junho. In: SOUSA, C. M. de. (Org.). Jornadas de junho: repercussões e leituras. Campina Grande: EDUEPB, 2013. p. 13-21.

MURANO, E. A linguagem dos protestos. Língua portuguesa. São Paulo, ano 8, n. 97, p. 26-33, ago. 2013.

NOBRE, M. Choque de democracia: razões da revolta. São Paulo: Companhia das Letras, 2013.

OESP - O ESTADO DE SÃO PAULO. Chegou a hora do basta. O Estado de São Paulo, São Paulo, 13 jun. 2013a, Notas \& Informações, p. A3.

Entender as manifestações. O Estado de São Paulo, São Paulo, 15 jun. 2013b, Notas \& Informações, p. A3.

"Sem violência" e sem controle. O Estado de São Paulo, São Paulo, 20 jun. 2013c, Notas \& Informações, p. A3.

PESSOA DE BARROS, M. L. O discurso da memória: entre o sensível e o inteligível. 2011. 307 f. Tese (Doutorado em Linguística) - Faculdade de Filosofia, Letras e Ciências Humanas, Universidade de São Paulo, São Paulo, 2011.

SECCO, L. As Jornadas de Junho. In: MARICATO, E. et al. Cidades rebeldes: passe livre e as manifestações que tomaram as ruas do Brasil. São Paulo: Boitempo; Carta Maior, 2013. p. 71-78.

VOLOSHINOV, V. Discourse in life and discourse in art - concerning sociological poetics. In. Freudism. Tradução de I. R. Titunik. New York: Academic Press, 1976. p. 93-116. (Tradução de Carlos Alberto Faraco e Cristovão Tezza, para fins didáticos. p. 1-19).

ZILBERBERG, C. Elementos da gramática tensiva. Tradução de Ivã Lopes, Luiz Tatit e Waldir Beividas. São Paulo: Ateliê Editorial, 2011.

Recebido em: 19/09/2017

Aprovado em: 28/06/2018 